\title{
PENGETAHUAN DAN SIKAP TENTANG TANDA BAHAYA DALAM KEHAMILAN SERTA KEAKTIFAN IBU DALAM KELAS IBU HAMIL
}

\author{
Nurfatimah, Lisa Fiarsi, Lisda Widianti Longgupa, Kadar Ramadhan \\ (Prodi D-III Kebidanan Poso, Jurusan Kebidanan, Poltekkes Kemenkes Palu)
}

\begin{abstract}
The implementation of pregnancy class in the Puskesmas Mapane in Poso Regency is still ineffective because it is done every three months. The purpose of this study to find out knowledge and attitudes about danger signs in pregnancy and the activeness of mothers in classes of pregnant women in the working area of Puskesmas Mapane in Poso Regency. Research methods using cross-sectional design. The population in this study were secondtrimester and third-trimester pregnant women in the working area of Puskesmas Mapane, 96 mothers. The sample in this study were 77 people who determined by simple random sampling. Chi square test is used to analyze the relationship between knowledge and attitudes with maternal activity in pregnant mother classes. The resultsshowed that from 77 people, there were $84.4 \%$ pregnant women who were not active in pregnancy class and pregnant women who had good knowledge and positive attitudes about the danger signs of pregnancy as many as $73.9 \%$. The conclusion is that the activeness of the mother in the class of pregnant women is not very influential in increasing the mother's knowledge about the danger signs of pregnancy. Suggestions are expected to the Puskesmas so that they can better provide information and motivation to pregnant women to take pregnancy class programs in their working areas.
\end{abstract}

Keywords: Activeness; Pregnancy Class; Danger Signs Of Pregnancy

\begin{abstract}
Abstrak
Pelaksanaan kelas ibu hamil di Puskesmas Mapane Kabupaten Poso masih belum efektif karena dilakukan setiap tiga bulan. Tujuan penelitian ini untuk mengetahui pengetahuan dan sikap tentang tanda-tanda bahaya pada kehamilan dan keaktifan ibu di kelas ibu hamil di wilayah kerja Puskesmas Mapane di Kabupaten Poso. Metode penelitian menggunakan desain cross-sectional. Populasi dalam penelitian ini adalah wanita hamil trimester kedua dan trimester ketiga di wilayah kerja Puskesmas Mapane, 96 ibu. Sampel dalam penelitian ini adalah 77 orang yang ditentukan dengan simple random sampling. Untuk menganalisis hubungan antara pengetahuan dan sikap dengan keaktifan ibu di kelas ibu hamil digunakan uji Chi square. Hasil penelitian menunjukkan bahwa dari 77 orang, ada 84,4\% wanita hamil yang tidak aktif di kelas ibu hamil dan ibu hamil yang memiliki pengetahuan yang baik dan sikap positif tentang tanda-tanda bahaya kehamilan sebanyak 73,9\%. Kesimpulannya adalah bahwa keaktifan ibu di kelas ibu hamil tidak terlalu berpengaruh dalam meningkatkan pengetahuan ibu tentang tanda-tanda bahaya kehamilan. Saran diharapkan kepada Puskesmas agar mereka dapat memberikan informasi dan motivasi yang lebih baik kepada ibu hamil untuk mengambil program kelas kehamilan di wilayah kerja mereka.
\end{abstract}

Kata kunci: Keaktifan; Kelas Ibu Hamil; Tanda-Tanda Bahaya Kehamilan.

\section{PENDAHULUAN}

Menurut laporan WHO 2015, secara global, diperkirakan 10,7 juta ibu meninggal dari 1990-2015 karena komplikasi kehamilan. Laporan ni menunjukkan bahwa kematian ibu di dunia (99\%) terjadi di negara-negara berkembang dan dua pertiga dari kematian ini terjadi di di Sub Sahara Afrika dimana mayoritas perempuan ini tidak memiliki pengetahuan tentang 
tanda-tanda bahaya dalam kehamilan. ${ }^{1}$ Meningkatkan kesadaran wanita tentang tanda bahaya kehamilan dan persalinan adalah langkah pertama agar ibu dapat menerima pelayanan kebidanan dengan rujukan yang tepat dan cepat. ${ }^{2,3}$

Keberhasilan upaya kesehatan ibu, di antaranya dapat dilihat dari indikator Angka Kematian Ibu (AKI). ${ }^{4}(\mathrm{KKI})$ menggambarkan jumlah wanita yang meninggal dari suatu penyebab kematian tanpa memperhitungkan lama kehamilan per 100.000 kelahiran hidup. Salah satu cara untuk mengurangi AKI yaitu dengan cara melakukan pemantauan saat kehamilan dan mengadakan kelas ibu hamil. ${ }^{5}$ Kelas Ibu hamil merupakan suatu program dari Kementrian Kesehatan Republik Indonesia dan merupakan kelompok belajar ibu hamil dengan umur kehamilan antara 20 minggu sampai dengan 32 minggu dengan jumlah peserta maksimal 10 orang. Kelas ibu hamil juga merupakan sarana untuk belajar bersama tentang kesehatan bagi ibu hamil yang bertujuan untuk meningkatkan pengetahuan, keterampilan ibu dan keluarga mengenai kehamilan. ${ }^{6,7}$

Hasil penelitian Nuryawati \& Budiasih tentang hubungan kelas ibu hamil dengan pengetahuan ibu hamil tentang tandabahaya kehamilan di desa Surawangi menemukan bahwa ibu hamil yang tidak aktif dalam kelas ibu hamil yaitu sebesar $70,2 \%$. Kurangnya keaktifan atau keikutsertaan ibu dalam kelas ibu hamil dikarenakan kurangnya informasi tentang adanya kelas ibu hamil, sibuk dengan pekerjaan, jarak yang terlalu jauh dan ibu kurang bersemangat dalam mengikuti kelas ibu hamil. ${ }^{8}$ Berdasarkan Profil Kesehatan Kabupaten Poso tahun 2018, tercatat ada 1 Angka Kematian lbu di Puskemas Mapane. Capaian kunjungan ibu hamil yang belum memenuhi target dari Dinas Kesehatan Kabupaten Poso salah satunya adalah Puskesmas Mapane yaitu K1 82,4\% dan K4 67,4\% dimana targetnya adalah $95 \% .^{9}$

Data dari wilayah kerja Puskesmas Mapane tahun 2018, jumlah cakupan ibu hamil sampai bulan Desember 2018 yaitu sebanyak 262 orang, sedangkan pada tahun 2019 jumlah cakupan ibu hamil sampai bulan Februari yaitu sebanyak 122 orang. Jumlah kelas ibu hamil diwilayah Puskesmas Mapane yaitu sebanyak 10 kelas ibu hamil yang diadakan selama 4 kali dalam dalam 1 tahun. Pelaksanaan kelas ibu hamil ini kurang efektif karena pelaksanaannya dilakukan setiap 3 bulan sekali karena berkaitan dengan adanya dana yang turun untuk pelaksanaan kelas ibu hamil tersebut. Jumlah ibu yang aktif mengikuti kelas ibu hamil sampai bulan Desember 2018, yaitu 58 orang. ${ }^{10}$

Studi pendahuluan yang dilakukan penulis pada salah satupetugas kesehatan di Puskesmas Mapane bahwa kurangnya keikutsertaan ibu dalam kelas ibu hamil dikarenakan ibu kurang mengetahui tentang jadwal pelaksanaan kelas ibu hamil dan terkendala masalah kendaraan atau tidak ada yang mengantar ibu untuk mengikuti pelaksanaan kelas ibu hamil. Keikutsertaan ibu pada kelas ibu hamil diharapkan dapat meningkatkan pengetahuan dan perubahan perilaku ibu hamil dan keluargaterhadap pentingnya pengenalan tanda bahaya 
dalam kehamilan. ${ }^{10}$ Tujuan penelitian ini adalah untuk mengetahui hubungan antara pengetahuan dan sikap tentang tanda bahaya dalam kehamilan dengan keaktifan ibu dalam kelas ibu hamil di wilayah kerja Puskesmas Mapane Kabupaten Poso.

\section{METODE PENELITIAN}

Desain yang digunakan dalam penelitian ini adalah metode analitik dengan pendekatan cross-sectional. Populasi dalam penelitian ini adalah ibu hamil trimester dua dan trimester tiga yang ada di wilayah kerja Puskesmas Mapane yaitu 96 orang. Sampel merupakan sebagian ibu hamil yang mengikuti kelas ibu hamil diwilayah kerja Puskesmas Mapane, yaitu berjumlah 77 orang.Teknik pengambilan sampel menggunakan simple random sampling. Pengumpulan data menggunakan kuesioner yang terdiri atas pertanyaan karakteristik responden, pengetahuan, sikap, dan keaktifan.Kriteria objektif dari pengetahuan yaitu baik jika skor $<75$, cukup $56-75$, dan kurang jika $<55$. Untuk variabel sikap positif jika skor $\geq 47$ (nilai median) dan negatif $<47$. Keaktifan aktif apabila ibu mengikuti kelas ibu hamil $\geq 3$ kali dan yang tidak aktif apabila $<3$ kali. Analisis yang digunakan secara univariat dan bivariat dengan uji Chi Square.

\section{HASIL PENELITIAN}

Tabel 1. Distribusi Frekuensi berdasarkan Umur, Paritas, Gravida, Pendidikan dan Pekerjaan Ibu Hamil di Wilayah Kerja Puskesmas Mapane

\begin{tabular}{llrc}
\hline \multicolumn{1}{c}{ Variabel } & \multicolumn{1}{c}{ Kategori } & $\mathrm{f}$ & Persentase \% \\
\hline Umur & $<20$ tahun & 4 & 5.2 \\
& 20-35 tahun & 64 & 83.1 \\
& $>35$ tahun & 9 & 11.7 \\
\hline Paritas & Nulipara & 19 & 24.7 \\
& Primipara & 27 & 35.1 \\
& Multipara & 29 & 37.7 \\
& Grande multipara & 2 & 2.6 \\
\hline Gravida & Primigravida & 19 & 24.7 \\
& Multigravida & 58 & 75.3 \\
\hline Pendidikan & SD & 10 & 13.0 \\
& SMP & 23 & 29.9 \\
& SMA & 34 & 44.2 \\
& PT/Diploma & 10 & 13.0 \\
\hline Pekerjaan & Bekerja & 9 & 11.7 \\
& Tidak Bekerja & 68 & 88.3 \\
\hline
\end{tabular}

Sumber : Data Primer, 2019

Tabel 1 menunjukkan mayoritas responden beumur 20 - 35 tahun $(22,6 \%)$, multipara $(37,7 \%)$, multigravida ( $75,3 \%)$ berpendidikan SMA $(44,2 \%)$ dan tidak bekerja $(88,3 \%)$. 
Tabel 2. Distribusi Pernyataan Pengetahuan Ibu tentang Tanda Bahaya dalam Kehamilan di Wilayah Kerja Puskesmas Mapane

\begin{tabular}{|c|c|c|c|c|c|}
\hline \multirow{2}{*}{ No } & \multirow{2}{*}{ Pernyataan } & \multicolumn{2}{|c|}{ Benar } & \multicolumn{2}{|c|}{ Salah } \\
\hline & & $\mathrm{n}$ & $\%$ & $\mathrm{n}$ & $\%$ \\
\hline 1 & Proses kehamilan adalah proses yang normal dan alamiah & 77 & 100 & 0 & 0 \\
\hline 2 & $\begin{array}{l}\text { Gejala pertama kehamilan yang ibu alami adalah } \\
\text { berhentinya siklus menstruasi normal }\end{array}$ & 76 & 98.7 & 1 & 1.3 \\
\hline 3 & $\begin{array}{l}\text { Pemeriksaan kehamilan dilakukan paling sedikit } 4 \text { kali } \\
\text { selama kehamilan }\end{array}$ & 65 & 84.4 & 12 & 15.6 \\
\hline 4 & $\begin{array}{l}\text { Tanda-tanda bahaya dalam kehamilan adalah tanda } \\
\text { bahaya yang terjadi selama kehamilan }\end{array}$ & 68 & 88.3 & 9 & 11.7 \\
\hline 5 & $\begin{array}{l}\text { Tanda bahaya dalam kehamilan merupakan gangguan } \\
\text { yang terjadi dalam proses kehamilan dan tidak } \\
\text { mengakibatkan komplikasi }\end{array}$ & 41 & 53.2 & 36 & 46.8 \\
\hline 6 & $\begin{array}{l}\text { Mual dan muntah yang berlebihan selama masa hamil } \\
\text { yang dapat menyebabkan terganggunya aktivitas } \\
\text { dan kelaparan adalah tanda bahaya kehamilan } \\
\text { Perdarahan vana keluar dari alat kemaluan ibu saat hamil }\end{array}$ & 64 & 83.1 & 13 & 16.9 \\
\hline 7 & $\begin{array}{l}\text { muda yang dapat berupa bercak-bercak atau } \\
\text { banyak adalah hal yang normal }\end{array}$ & 23 & 29.9 & 54 & 70.1 \\
\hline 8 & $\begin{array}{l}\text { Perdarahan pada hamil lanjut atau tua bukan merupakan } \\
\text { tanda bahaya yang mengancam kesehatan ibu dan janin }\end{array}$ & 32 & 41.6 & 45 & 58.4 \\
\hline 9 & $\begin{array}{l}\text { Sakit kepala menetap yaitu sakit kepala yang tidak hilang } \\
\text { meskipun dengan beristrahat merupakan gejala adanya } \\
\text { tanda bahaya kehamilan }\end{array}$ & 69 & 89.6 & 8 & 10.4 \\
\hline 10 & $\begin{array}{l}\text { Bengkak pada bagian kaki, tangan dan } \\
\text { wajah adalah salah satu tanda bahaya dalam kehamilan }\end{array}$ & 68 & 88.3 & 9 & 11.7 \\
\hline 11 & $\begin{array}{l}\text { Nyeri perut yang hebat saat hamil bukan termasuk } \\
\text { kedalam tanda bahaya dalam kehamilan } \\
\text { Jika } 6-8 \text { jam bayi dalam kandungan tidak bergerak atau }\end{array}$ & 23 & 29.9 & 54 & 70.1 \\
\hline 12 & $\begin{array}{l}\text { gerakannya berkurang tidak seperti biasanya merupakan } \\
\text { tanda adanya masalah kesehatan pada janin }\end{array}$ & 70 & 90.9 & 7 & 9.1 \\
\hline 13 & $\begin{array}{l}\text { Pandangan mata yang kabur atau berbayang secara } \\
\text { mendadak merupakan gejala yang normal }\end{array}$ & 31 & 40.3 & 46 & 59.7 \\
\hline 14 & $\begin{array}{l}\text { Peningkatan suhu tubuh pada saat hamil merupakan } \\
\text { suatu hal yang normal }\end{array}$ & 54 & 70.1 & 23 & 29.9 \\
\hline 15 & $\begin{array}{l}\text { Ketuban pecah sebelum waktunya apabila selaput } \\
\text { ketuban pecah sebelum persalinan berlangsung }\end{array}$ & 62 & 80.5 & 15 & 19.5 \\
\hline
\end{tabular}

Tabel 2 menunjukanmayoritas reponden menjawab benar pernyataan pengetahuan nomor $1(100 \%)$, nomor $2(98,7 \%)$, nomor $3(84,4 \%)$, nomor $4(88,3)$, nomor $5(53,2 \%)$, nomor 6 (83,1\%), nomor 9 (89,6\%), nomor $10(88,3 \%)$, nomor $12(90,9 \%)$, nomor 14 $(70,1 \%)$, dan nomor $15(80,5 \%)$. Mayoritas responden menajwab salah pada pernyataan pengetahuan nomor $7(70,1 \%)$, nomor $8(58,4 \%)$, nomor $11(70,1 \%)$, dan nomor $13(59,7 \%)$. 
Tabel 3. Distribusi Pernyataan Sikap Ibu tentang Tanda Bahaya dalam Kehamilan di Wilayah Kerja Puskesmas Mapane

\begin{tabular}{|c|c|c|c|c|c|c|c|c|c|}
\hline \multirow{2}{*}{ No } & \multirow{2}{*}{ Pernyataan } & \multicolumn{2}{|c|}{ SS } & \multicolumn{2}{|c|}{ S } & \multicolumn{2}{|c|}{ TS } & \multicolumn{2}{|c|}{ STS } \\
\hline & & 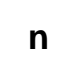 & $\%$ & $\mathbf{n}$ & $\%$ & $\mathbf{n}$ & $\%$ & $\mathbf{n}$ & $\%$ \\
\hline 1 & $\begin{array}{l}\text { Melakukan deteksi dini tanda bahaya } \\
\text { kehamilan bertujuan untuk mengenali tanda } \\
\text { bahaya kehamilan }\end{array}$ & 50 & 64.9 & 27 & 35.1 & 0 & 0 & 0 & 0 \\
\hline 2 & $\begin{array}{l}\text { Periksa kehamilan atau kunjungan } \\
\text { kehamilan dilakukan jika kehamilan } \\
\text { mempunyai risiko terhadap persalinan } \\
\text { Sebaiknya deteksi dini tanda-tanda bahaya }\end{array}$ & 4 & 5.2 & 36 & 46.8 & 18 & 23.4 & 19 & 24.7 \\
\hline 3 & $\begin{array}{l}\text { kehamilan dapat dilakukan minimal } 4 \text { kali } \\
\text { selama kehamilan berlangsung } \\
\text { Pada awal kehamilan atau kehamilan muda }\end{array}$ & 32 & 41.6 & 41 & 53.2 & 4 & 5.2 & 0 & 0 \\
\hline 4 & $\begin{array}{l}\text { tidak perlu dilakukan pemeriksaan } \\
\text { kehamilan }\end{array}$ & 13 & 16.9 & 56 & 72.7 & 7 & 9.1 & 1 & 1.3 \\
\hline 5 & $\begin{array}{l}\text { Melakukan penanganan sendiri seperti } \\
\text { minum ramuan tradisional jika selama } \\
\text { kehamilan mengalami nyeri perut yang } \\
\text { hebat dan perdarahan }\end{array}$ & 29 & 37.7 & 40 & 51.9 & 6 & 7.8 & 2 & 2.6 \\
\hline 6 & $\begin{array}{l}\text { Pemeriksaan kehamilan pada trimester II } \\
\text { (13-28minggu) dilakukan sebanyak } 1 \text { kali } \\
\text { Berat badan ibu dapat terganggu selama }\end{array}$ & 21 & 27.3 & 44 & 57.1 & 7 & 9.1 & 5 & 6.5 \\
\hline 7 & $\begin{array}{l}\text { kehamilan berlangsung disebabkan oleh } \\
\text { faktor keturunan yang dialami oleh ibu } \\
\text { tersebut } \\
\text { lbu akan melakukan pemeriksaan }\end{array}$ & 15 & 19.5 & 37 & 48.1 & 19 & 24.7 & 6 & 7.8 \\
\hline 8 & $\begin{array}{l}\text { kehamilan segera apabila bayi dalam } \\
\text { kandungannya bergerak kurang dari } 3 \text { kali } \\
\text { dalam periode } 3 \text { jam }\end{array}$ & 20 & 26.0 & 44 & 57.1 & 10 & 13.0 & 3 & 3.9 \\
\hline 9 & $\begin{array}{l}\text { Pandangan kabur atau rabun senja } \\
\text { merupakan kejadian hal yang sudah biasa } \\
\text { dalam kehamilan sehingga tidak butuh } \\
\text { penanganan yang tepat oleh tenaga } \\
\text { kesehatan }\end{array}$ & 22 & 28.6 & 36 & 46.8 & 13 & 16.9 & 6 & 7.8 \\
\hline 10 & $\begin{array}{l}\text { Pandangan kabur atau rabun senja } \\
\text { merupakan kejadian hal yang tidak biasa }\end{array}$ & 25 & 325 & 44 & 571 & 7 & 91 & 1 & 13 \\
\hline & $\begin{array}{l}\text { penanganan yang tepat oleh tenaga } \\
\text { kesehatan } \\
\text { Anemia (kekurangan darah) pada }\end{array}$ & & 32.5 & 44 & $5 / .1$ & $r$ & 9.1 & 1 & 1.3 \\
\hline 11 & $\begin{array}{l}\text { kehamilan merupakan hal yang alamiah } \\
\text { selama kehamilan berlangsung. } \\
\text { Pecahnya ketuban sebelum waktunya }\end{array}$ & 15 & 19.5 & 43 & 55.8 & 18 & 23.4 & 1 & 1.3 \\
\hline 12 & $\begin{array}{l}\text { Pecannya ketuban sebelum waktunya } \\
\text { merupakan salah satu deteksi dini tanda } \\
\text { bahaya kehamilan pada trimester ketiga ( } 29 \\
\text { minggu-40minggu) }\end{array}$ & 28 & 36.4 & 42 & 54.4 & 5 & 6.5 & 2 & 2.6 \\
\hline 13 & $\begin{array}{l}\text { lbu segera meminta bantuan atau } \\
\text { pertolongan kepada dukun bayi apabila } \\
\text { mengalami nyeri pada perut nya selama } \\
\text { masa kehamilan }\end{array}$ & 46 & 59.7 & 25 & 32.5 & 4 & 5.2 & 2 & 2.6 \\
\hline 14 & $\begin{array}{l}\text { lbu segera meminta bantuan atau } \\
\text { pertolongan kepada bidan apabila } \\
\text { mengalami nyeri pada perutnya selama } \\
\text { masa kehamilan } \\
\text { lbu tidak perlu melakukan memeriksakan }\end{array}$ & 48 & 62.3 & 23 & 29.9 & 5 & 6.5 & 1 & 1.3 \\
\hline 15 & $\begin{array}{l}\text { kehamilan apabila ibu tidak mengalami } \\
\text { tanda bahaya kehamilan }\end{array}$ & 17 & 22.1 & 40 & 51.9 & 13 & 16.9 & 7 & 9.1 \\
\hline
\end{tabular}

Sumber : Data Primer, 2019 
Tabel 3 menunjukan mayoritas responden menyatakan sangat setuju pada pernyataan nomor 1 (64,9\%), nomor 13 (59,7\%), dan nomor 14 (62,3\%). mayoritas responden menyatakan setuju pada pernyataan nomor $2(46,8 \%)$, nomor $3(53,2 \%)$, nomor $4(72,7 \%)$, nomor $5(51,9 \%)$, nomor $6(57,1 \%)$, nomor $7(48,1 \%)$, nomor $8(57,1 \%)$, nomor $9(46,8 \%)$, nnomor 10 (57,1\%), nomor 11 (55,8\%), nomor $12(54,4 \%)$, dan nomor 15 (51,9\%).

$\begin{aligned} & \text { Tabel 4. Distribusi Frekuensi Pengetahuan Tentang Tanda Bahaya } \\
& \text { Dalam Kehamilan di Wilayah Kerja Puskesmas Mapane }\end{aligned}$
\begin{tabular}{lcc} 
Kecamatan Poso Pesisir Utara Kabupaten Poso \\
\hline Pengetahuan & $\mathbf{n}$ & $\%$ \\
\hline Baik & 46 & 59.7 \\
Cukup & 27 & 35.1 \\
Kurang & 4 & 5.2 \\
\hline Sikap & & \\
\hline$\quad$ Positif & 43 & 55.8 \\
Negatif & 34 & 44.2 \\
\hline Keaktifan & & \\
\hline Aktif & 12 & 15.6 \\
Tidak Aktif & 65 & 84.4 \\
\hline
\end{tabular}

Sumber : Data Primer, 2019

Tabel 4 menunjukkan mayoritas responden memiliki pengetahuan baik $(59,7 \%)$, sikap positif $(55,8 \%)$, dan tidak aktif $(84,4 \%)$.

Tabel 5. Hubungan Pengetahuan dan Sikap tentang Tanda Bahaya dalam Kehamilan dengan Keaktifan Ibu dalam Kelas Ibu Hamil di Wilayah Kerja Puskesmas Mapane

\begin{tabular}{|c|c|c|c|c|c|c|c|}
\hline \multirow[t]{2}{*}{ Variabel } & \multicolumn{4}{|c|}{ Keaktifan } & \multirow{2}{*}{\multicolumn{2}{|c|}{ Jumlah }} & \multirow[b]{2}{*}{$\mathrm{p}$} \\
\hline & \multicolumn{2}{|c|}{$\mathrm{Ya}$} & \multicolumn{2}{|c|}{ Tidak } & & & \\
\hline Pengetahuan & $n$ & $\%$ & $n$ & $\%$ & $n$ & $\%$ & \\
\hline Baik & 7 & 15.2 & 39 & 84.8 & 46 & 100 & \\
\hline Cukup & 5 & 18.5 & 22 & 81.5 & 27 & 100 & 0,631 \\
\hline Kurang & 0 & 0.0 & 4 & 100,0 & 4 & 100 & \\
\hline Sikap & & & & & & & \\
\hline Positif & 9 & 20.9 & 34 & 79.1 & 43 & 100 & \\
\hline Negatif & 3 & 8.8 & 31 & 91.2 & 34 & 100 & 0,255 \\
\hline
\end{tabular}

Sumber : Data Primer, 2019

Tabel 5 menunjukkan mayoritas ibu hamil yang memiliki pengetahuan cukup, aktif mengikuti kelas ibu hamil (18,5\%) dan sikap positif, aktif mengikuti kelas ibu hamil $(20,9 \%)$.Hasil uji chi square menunjukkan tidak ada hubungan antara pengetahuan dan sikap tentang tanda bahaya kehamilan dengan keaktifanibu dalam kelas ibu hamil dengan nilai $p=0,631$ untuk pengetahuan dan nilai $p=0,255$ untuk sikap. 


\section{PEMBAHASAN}

\section{A. Keaktifan Ibu dalam Kelas Ibu Hamil}

Menurut Notoatmodjo keaktifan berarti keikutsertaan ibu hamil serta keluarga/suami dalam mengikuti, mendukung, dan serta ikut merasakan hasil dari program kelas ibu hamil yang dilaksanakan oleh petugas kesehatan. Dalam hal ini, masyarakat sendirilah yang aktif memikirkan, merencanakan, melaksanakan, dan mengevaluasi program-program kesehatan masyarakatnya. Institusi kesehatan hanya sekedar memotivasi dan membimbingnya. ${ }^{11}$ Penelitian diatas sejalan dengan penelitian yang dilakukan oleh Nuryawati\& Budiasih yang menemukan bahwa kurangnya keaktifan atau keikutsertaan ibu dalam kelas ibu hamil dikarenakan kurangnya informasi tentang adanya kelas ibu hamil, jarak yang terlalu jauh dan ibu kurang bersemangat dalam mengikuti kelas ibu hamil. ${ }^{8}$

\section{B. Pengetahuan dan Keaktifan}

Pengetahuan adalah hasil dari tahu dan pengetahuan terjadi setelah seseorang melakukan suatu pengindraan terhadap kejadian tertentu. Sebagian pengetahuan manusia dapat diperoleh melalui mata dan telinga. ${ }^{12}$ Hasil penelitian menunjukan bahwa lebih dari separuh responden memiliki pengetahuan yang baik dalam mengenal tanda bahaya kehamilan. Untuk variabel pengetahuan reponden paling banyak belum mengetahui tentang nyeri perut hebat saat hamil bukan termasuk kedalam tanda bahaya dalam kehamilan. Terkait tanda bahaya dalam kehamilan nyeri perut hebat merupakan salah satu tanda bahaya kehamilan yang dapat mengancam keselamatan ibu dan janin serta harus mendapatkan penanganan segera oleh tenaga kesehatan, sedangkan untuk jawaban benar orang paling banyak menjawab terkait pernyataan proses kehamilan adalah proses yang normal dan alamiah. Pengetahuan orang dapat diperoleh dari penyuluhan-penyuluhan, melihat media cetak dan elektronik sedangkan pengetahuan yang kurang disebabkan karena kurangnya informasi yang mereka terima dan kurangnya motivasi diri untuk mengetahui hal tersebut.

Hasil penelitian diatas sejalan dengan penelitian yang dilakukan Sasnitiari \& Puspitasari, menemukan bahwa semakin sering ibu mendapatkan informasi maka akan meningkatkan keingintahuan ibu tentang tanda bahaya kehamilan dan meningkatkan pengetahuan ibu tentang tanda bahaya kehamilan. ${ }^{13}$ Keikutsertaan atau partisipasi seseorang untuk mengikuti suatu kegiatan dipengaruhi oleh beberapa faktor yaitu salah satunya kurangnya pengetahuan. Sehingga kurangnya pengetahuan mempengaruhi seseorang untuk berpartisipasi dalam suatu kegiatan yaitu kelas ibu hamil. Terkait masalah kelas ibu hamil dengan pengetahuan ibu yang cukup lebih termotivasi untuk ikut serta dalam kelas ibu hamil guna meningkatkan kondisi kesehatan dan pengetahuan selama kehamilan. ${ }^{14}$ 
Rendahnya frekuensi tentang keaktifan ibu dan pengetahuannya dikarenakan waktu pelaksanaan kelas ibu hamil yang kurang efektif. Adapun hambatan dari kurangnya partisipasi dalamkelas ibu hamil dikarenakan ibu hamil tidaktahu adanya kelas ibu hamil di wilayahnya,serta ibu hamil yang bekerja.Dari hasil penelitian bahwa frekuensi terbanyak yaitu pengetahuan baik tapi tidak aktif dalam kelas ibu hamil, pengetahuan ibu hamil tentang tanda bahaya kehamilan bisa ibu dapatkan atau diperoleh dari penyuluhan-penyuluhan, melihat media cetak dan elektronik, dalam hal ini keikutsertaan ibu tidak begitu berpengaruh dalam meningkatkan pengetahuan.

Penelitian ini sejalan dengan penelitian yang dilakukan Risneni \& Yenie menunjukkan bahwa pengetahuan ibu hamil bukan hanya dilihat dari keaktifan ibu dalam mengikuti kelas ibu hamil tetapi bisa dilihat dari bagaimana ibu hamil dapat menerima dan mendapatkan pengetahuan yang berbeda-beda seperti dengan cara banyak membaca buku-buku dan dapat memperoleh informasi baik dari media cetak maupun elektronik. ${ }^{15}$

\section{Sikap dan Keaktifan}

Sikap adalah suatu proses penilaian yang dilakukan seseorang terhadap suatu objek atau situasi yang disertai adanya perasaan tertentu dan memberikan dasar kepada orang tersebut untuk membuat respons atau berperilaku dalam cara tertentu yang dipilihnya. ${ }^{16}$ Hasil penelitian menunjukan bahwa lebih dari separuh responden memiliki sikap yang positif dalam mengenal tanda bahaya kehamilan. Untuk variabel sikap, dari pernyataan positif orang paling banyak menjawab sangat setuju terkait pernyataan, melakukan deteksi dini tanda bahaya kehamilan bertujuan untuk mengenali tanda bahaya kehamilan deteksi dini tanda bahaya kehamilan, sedangkan untuk pernyataan negatif orang paling banyak menjawab terkait pernyataan, pada awal kehamilan atau kehamilan muda tidak perlu dilakukan pemeriksaan kehamilan, sementara pada kehamilan muda ibu perlu memeriksakan dirinya untuk mendeteksi secara dini tentang kehamilannya.

Hasil penelitian diatas sejalan dengan penelitian yang dilakukan Sasnitiari\& Puspitasari menunjukkan bahwa sebagian besar ibu hamil memiliki sikap yang positif terhadap tanda bahaya kehamilan disebabkan karena ibu mendapatkan informasi atau pengetahuan yang baik tentang tanda bahaya kehamilan. Semakin baik pengetahuan tentang tanda bahaya kehamilan maka semakin baik sikap ibu tentang tanda bahaya kehamilan. ${ }^{13}$ Keikutsertaan ibu hamil dalam kegiatan kelas ibu hamil merupakan suatu bentuk perilaku, karena perilaku manusia pada hakekatnya adalah suatu aktivitas dari manusia itu sendiri. Perilaku ibu hamil yang mengunjungi kelas ibu hamil adalah perilaku kesehatan yaitu hal-hal yang berkaitan dengan tindakan atau kegiatan seseorang dalam memelihara dan meningkatkan kesehatannya. ${ }^{17}$

Hasil penelitian menunjukkan bahwa ibu mayoritas yang aktif dalam kelas ibu hamil memiliki sikap positif. Penelitian ini sejalan dengan peneltian yang dilakukan Masini bahwa 
Ibu hamil yang memiliki sikap negatif atau kurang mendukung terhadap pelaksanaan kelas ibu hamil lebih berisiko untuk tidak berpartisipasi dalam kelas ibu hamil Ibu. ${ }^{18}$ Penelitian ini sejalan dengan penelitian yang dilakukan oleh Yuliantika bahwa Ibu hamil yang memiliki sikap kurang baik atau kurang mendukung terhadap pelaksanaan kelas ibu hamil lebih berisiko untuk tidak berpartisipasi dalam kelas ibu hamil dibandingkan dengan ibu yang mempunyai sikap baik atau mendukung pelaksanaan kelas ibu hamil. ${ }^{19}$

\section{SIMPULAN DAN SARAN}

Pengetahuan dan sikap tentang tanda bahaya dalam kehamilan tidak berhubungan dengan Keaktifan Ibu dalam kelas ibu hamil. Peneliti mengharapkan kepada pihak Puskesmas agar bisa lebih memberikan informasi dan motivasi kepada ibu hamil untuk mengikuti program kelas ibu hamil di wilayah kerjanya.

\section{DAFTAR PUSTAKA}

1. Geleto A, Chojenta C, Musa A, Loxton D. WOMEN's Knowledge of Obstetric Danger signs in Ethiopia (WOMEN's KODE):a systematic review and meta-analysis. Syst Rev. 2019 Dec 25;8(1):63.

2. Hailu D, Berhe H. Knowledge about Obstetric Danger Signs and Associated Factors among Mothers in Tsegedie District, Tigray Region, Ethiopia 2013: Community Based Cross-Sectional Study. Carlo WA, editor. PLoS One. 2014 Feb 6;9(2):e83459.

3. Amenu G, Mulaw Z, Seyoum T, Bayu H. Knowledge about Danger Signs of Obstetric Complications and Associated Factors among Postnatal Mothers of Mechekel District Health Centers, East Gojjam Zone, Northwest Ethiopia, 2014. Scientifica (Cairo). 2016;2016:1-7.

4. Kementerian Kesehatan R.I. Profil Kesehatan Indonesia 2015. Jakarta; 2016.

5. InfoDATIN. Mother's Day. Situasi Kesehatan Ibu. Jakarta; 2018.

6. Kementerian Kesehatan R.I. Pedoman Pelaksanaan Kelas Ibu Hamil. Jakarta: Direktorat Jenderal Bina Gizi dan KIA; 2014.

7. Chasanah U, Ratifah. Hubungan Pengetahuan Ibu Hamil tentang Kelas Ibu Hamil dengan Motivasi Mengikuti Kelas Ibu Hamil di Puskesmas 2 Mandiraja Kabupaten Banjarnegara. Bidan Prada J IIm Kebidanan. 2013;4(1):211-9.

8. Nuryawati LS, Budiasih S. Hubungan Kelas Ibu Hamil dengan Pengetahuan Ibu Hamil Tentang Tanda-Tanda Bahaya Kehamilan di Desa Surawangi Wilayah Kerja UPTD Puskesmas Jatiwangi Kabupaten Majalengka Tahun 2016. J Bidan "Midewife Journal." 2017;3(1):60-6.

9. Dinas Kesehatan Kabupaten Poso. Laporan Kesehatan Ibu dan Anak. 2018.

10. Puskesmas Mapane. Laporan PWS-KIA Tahun 2018. Poso; 2019. 
11. Notoatmodjo S. Promosi Kesehatan dan Perilaku Kesehatan. Revisi 201. Jakarta: Rineka Cipta; 2014.

12. Notoatmodjo S. Ilmu Perilaku Kesehatan. Jakarta: Rineka Cipta; 2010.

13. Sasnitiari NN, Puspitasari DA. Hubungan Keikutsertaan Ibu pada Kelas lbu Hamil dengan Pengetahuan dan Sikap Ibu Terhadap Tanda-tanda Bahaya Kehamilan di Kota Bogor. J Kesehat Reproduksi. 2017;8(2).

14. Martinda B, Anggrainy ED. Hubungan Pengetahuan Ibu Hamil terhadap Keikutsertaan dalam Kelas Ibu Hamil di Pos Kesehatan Desa Palur. J Matern. 2014;1(2).

15. Risnaeni, Yenie H. Faktor-Faktor Yang Berhubungan Dengan Kehadiran Ibu Hamil Pada Kelas Ibu Di Satu Kecamatan Kabupaten Lampung Selatan. J IIm Keperawatan Sai Betik. 2017;13(1).

16. Lestari T. Kumpulan Teori Untuk Kajian Pustaka Penelitian Kesehatan. Jogjakarta: Nuha Medika; 2015.

17. Emiyanti, Rahfiludin MZ, Winarni S. Analisis Faktor yang Berhubungan dengan Keikutsertaan Kelas Ibu Hamil Januari-Juli Tahun 2017 (Studi di Kecamatan Muara Tembesi Kabupaten Batang Hari Provinsi Jambi). J Kesehat Masy. 2017;5(4):801-11.

18. Masini, Idhayanti RI. Pengaruhi Umur, Tingkat Pengetahuan, Sikap Terhadap Partisipasi Ibu Dalam Kelas Ibu Hamil di Kabupaten Magelang. J Ilmu Teknol Kesehat Bhamada. 2015;6(1).

19. Yuliantika. Faktor yang Berhubungan Dengan Partisipasi lbu Hamil Resiko Tinggi dalam Mengikuti Program Kelas Ibu hamil di Wilayah Kerja Puskesmas Sukolilo. Universitas Negeri Semarang; 2016. 